\title{
Development of controllers for a nonlinear quarter car active suspension system
}

\begin{abstract}
In this paper, the development of automatic controllers for an active suspension system using a quarter car model is described. The main aim of the controller is to minimise the body displacement, velocity and acceleration while keeping the rattle space and other movement and forces related to the suspension system in their limited ranges. The suspension system is difficult to control since the characteristics of spring, damping force, 'tyre lift' and the road model are mostly nonlinear. A passive suspension system responds only to the deflection of the strut, while the active system setup can put energy into the system at an appropriate time, in a way or amount that is right for all the variables in the system.
\end{abstract}

Keyword: Active suspension; Controller design; Fuzzy logic; Hybrid control; Nonlinear systems; Quarter car models; Vehicle suspensions; Fuzzy control 